\title{
A Retrospective Analysis of Ki-67 Index and its Prognostic Significance in Over 800 Primary Breast Cancer Cases
}

\author{
FABINSHY THANGARAJAH ${ }^{1}$, INSA ENNINGA ${ }^{1}$, WOLFRAM MALTER ${ }^{2}$, STEFANIE HAMACHER $^{3}$, \\ BIRGID MARKIEFKA ${ }^{4}$, LISA RICHTERS ${ }^{1}$, STEFAN KRÄMER $^{5}$, PETER MALLMANN $^{1}$ and VERENA KIRN ${ }^{1,2}$ \\ Departments of ${ }^{1}$ Obstetrics and Gynecology, and ${ }^{4}$ Pathology, and ${ }^{2}$ Breast Center, \\ University Hospital of Cologne, Cologne, Germany; \\ ${ }^{3}$ Institute of Medical Statistics, Informatics and Epidemiology, University of Cologne, Cologne, Germany; \\ ${ }^{5}$ Breast Center, Helios Clinic Krefeld, Krefeld, Germany
}

\begin{abstract}
Background/Aim: The Ki-67 index is chiefly important for distinguishing between luminal $A$ and luminal $B$ human epidermal growth factor receptor 2 (HER2neu)negative breast cancer subtypes. However, its ability to predict response to chemotherapy is uncertain. Patients and Methods: Patients treated for primary breast cancer at the University Hospital of Cologne were identified. Immunohistochemistry for Ki-67 detection was performed according to standard protocols. Kaplan-Meier survival curves were calculated and compared using the log-rank test. Results: Patients with low Ki-67 index had a significantly better disease-free-survival (DFS) than patients with high Ki-67 index (hazard ratio=2.85; $95 \%$ confidence interval $=1.45-5.59 ; p=0.002)$. A significant influence on DFS was demonstrated (hazard ratio $(H R)=1.02$; confidence interval $(C I)=1.00-1.04 ; p=0.048)$ within the subgroup of hormone receptor-positive and HER2neu-negative patients, but not within the subgroup of those with luminal B/HER2neu-negative tumors (DFS: $p=0.801$; overall-survival: $p=0.379)$. Conclusion: The Ki-67 index has a prognostic impact on DFS in patients with hormone receptor-positive and HER2neu-negative tumors. The strict cut-off value was not suitable for distinguishing between high-and low-risk patients and their response to adjuvant chemotherapy.
\end{abstract}

The Ki-67 index is a well-known proliferation marker that was first detected in 1983 by a German study group (1). This nuclear antigen is expressed in the $G_{1}, S, G_{2}$ and $M$ cellcycle phases. During these phases the level of expression varies: levels are low in $G_{1}$ and early $S$ phase and increase

Correspondence to: Fabinshy Thangarajah, University Hospital of Cologne, Department of Obstetrics and Gynecology, Kerpener Str. 34, 50931 Cologne, Germany. Tel: +49 2214784910, Fax: +49 22147886546, e-mail: Fabinshy.Thangarajah@uk-koeln.de

Key Words: Predictive factors, Ki-67 index, prognosis, IHC. to a maximum at the time of mitosis (2-5). A rapid decrease in Ki-67 expression occurs in anaphase and telophase $(4,5)$. In order to identify cells expressing the Ki-67 protein, immunohistochemistry is usually performed using a mouse monoclonal antibody. The MIB-1 antibody has been validated most frequently $(4,6,7)$.

The Ki-67 index is considered to be important for distinguishing between luminal $\mathrm{A}$ and luminal $\mathrm{B} /$ human epidermal growth factor receptor 2 (HER2neu) negative breast cancer subtypes $(8,9)$. However, its ability to predict response to chemotherapy is controversial $(4,10)$, even though several studies confirmed the prognostic impact of Ki-67 index in breast cancer $(8,11-18)$.

Hence, the use of $\mathrm{Ki}-67$ index in clinical routine has been discussed controversially. Polley et al. examined the reproducibility of Ki-67 index within different laboratories. This study group stated a high reproducibility within those laboratories, but a moderate high reproducibility between laboratories of different institutions (19). Due to this variability and low validity of Ki-67 index measurement, the authors concluded that cut-off values for the Ki-67 index should not be used without any standardization of measurement. Another study also reported a high inter- and intra-observer variability of Ki-67 indices between 10-20\% (20). The German Working Group for Gynecologic Oncology of 2014 emphasized that the $\mathrm{Ki}-67$ index is not able to distinguish between low- and high-risk groups within the luminal subgroup. Nevertheless, the Working Group for Gynecologic Oncology accepted there being a prognostic impact of $\mathrm{Ki}-67$ index in breast cancer and considers the $\mathrm{Ki}-67$ index as a good predictor of response to neoadjuvant therapy (21). The predictive impact of the Ki-67 index in endocrine therapy is unclear. The American Society of Clinical Oncology discourages the use of the Ki-67 index as a prognostic factor (6). The prognostic and predictive impact of the Ki-67 index seems to be unclear. 
We aimed to analyze the disease-free (DFS) and overall (OS) survival of patients with breast cancer in tertiary singlecenter institution regarding low, intermediate and high Ki-67 indices. In addition, we aimed to analyze whether a cut-off value of $14 \%$ for the Ki-67 index is able to distinguish between high- and low-risk breast cancer and predicts the outcome of intrinsic subgroups in our single-center cohort. Within the subgroup of hormone-receptor-positive and HER2neu-negative $\left(\mathrm{HR}^{+} / \mathrm{HER} 2 \mathrm{neu}^{-}\right)$breast cancer the strict cut-off of $14 \%$ was evaluated to distinguish between luminal $\mathrm{A}$ and luminal B/HER2neu $\mathrm{u}^{-}$tumors. In particular, the comparison of outcome between those who received chemotherapy and those who did not was of clinical interest.

\section{Patients and Methods}

Patients. A total of 3022 patients with breast cancer that were treated at the Breast Center of the University of Cologne, Department of Obstetrics and Gynecology, between 2004 and 2013 were identified retrospectively from our tumor documentation program ODSeasy (Asthenis $\mathrm{GmbH}$, Munich, Germany). We documented age at diagnosis, date of diagnosis, menopausal status, tumor stage, grade, hormone and HER2neu receptor status, Ki-67 index of the core biopsy, any kind of therapy, and follow-up data. Data that were not available through ODSeasy were abstracted from the patients' charts. Those patients with primary metastatic disease, ductal carcinoma in situ or lobular carcinoma in situ, bilateral breast cancer, male gender, or patients with missing tumor grade, hormone receptor status or follow-up data were excluded from analysis.

Immunohistochemistry. Immunohistochemistry for Ki-67 detection was performed at the Institute of Pathology of the University Hospital of Cologne. Formalin-fixed and paraffin-embedded tumor tissue was used, which underwent standard protocol: initial treatment of specimens in citrate buffer ( $\mathrm{pH}$ 6.0) for 10-12 min followed by 20 min cooling. The actual staining was performed by a Bond III automated immunstainer (Leica Biosystems, Nussloch, Germany). Quantitative evaluation was performed by an experienced gynecologic pathologist.

Statistical analysis. Patient characteristics are described using count (percentage), mean \pm standard deviation (SD) or median [interquartile range (IQR)], as appropriate.

In the first part of the analysis, the breast cancer cases were divided into three subgroups according to Ki-67 index as low $(<10 \%)$, intermediate $(10 \%-20 \%)$ and high $(>20 \%)$, whereas in the second part of the analysis, all cases were divided into four intrinsic subgroups of luminal A tumors, luminal B tumors, HER2neu+/nonluminal tumors and basal-like tumors. A strict cut-off Ki67 index of $14 \%$ was chosen for distinguishing between luminal A luminal B tumors.

Possible associations of absolute $\mathrm{Ki}-67$ index with grading, Tstage and $\mathrm{N}$-stage were evaluated with Spearman correlation and coefficients of correlation (r) and $p$-values are reported. Fisher's exact test was used in the luminal B/HER2neu ${ }^{-}$subgroup to test for associations between chemotherapy and T-stage and nodal status. For this, odds ratio (OR), corresponding $95 \%$ confidence interval (CI) and $p$-values are presented.
Kaplan-Meier estimates for DFS and OS were calculated and compared by log-rank test. Local recurrence, recurrence in axillary lymph nodes, distant metastasis and death were considered as events for DFS. OS was defined as time between diagnosis and death. Patients without an event or who were lost to follow-up were censored.

Proportional hazards assumption were checked and multiple Cox regression models adjusted for T-stage (T1/T2 vs. T3/T4), N-stage (N0 vs. N+, HER2neu status and received adjuvant therapy (endocrine therapy, radiation and chemotherapy) were computed. Resulting hazard ratios (HR), corresponding 95\% CIs and $p$-values (Wald test) are presented.

All reported $p$-values are two-sided and considered statistically significant if 0.05 or less. Statistical analysis was performed with SPSS Statistics 23 (IBM Corp., Armonk, NY, USA).

\section{Results}

A total of 802 patients were included in this analysis, with a median follow-up of 39 months (range=3-121 months). Most patients were postmenopausal $(64.5 \%)$ and the most frequent T-stage was T1 (64\%). Overall, 70.8\% of the cohort was negative for lymph node metastases. An overview of basic histopathological data is presented in Table I. The mean age of patients was $57.5 \pm 11.9$ years; $54.1 \%$ of the cohort received chemotherapy; $59.7 \%$ underwent a breastconserving therapy, whereas $23.6 \%$ underwent mastectomy; $67.2 \%$ received an endocrine therapy and $78.2 \%$ underwent radiation therapy. Table I also shows an overview of the distribution of received adjuvant therapy.

During follow-up time, 16 patients died, 31 patients experienced local and nine patients axillary recurrence, and 45 patients developed distant metastases.

Ki-67 index and correlations. The median Ki-67 index was $10 \%$ (IQR $=5 \%-20 \%)$ and the mean $\mathrm{Ki}-67$ index was $14.7 \% \pm 14.2 \%$. A total of 333 patients had a low Ki-67 index $(<10 \%), 326$ patients had an intermediate Ki-67 index (10$20 \%)$, whereas 143 patients had a high Ki-67 index (>20\%) (Table I).

Ki-67 index correlated significantly with grading $(\mathrm{r}=0.420 ; p<0.001)$. Significant positive correlation was also found between Ki-67 index and T-stage $(\mathrm{r}=0.139 ; p<0.001)$ and between Ki-67 index and nodal status $(r=0.119$; $p=0.001$ ).

Subgroup analysis according to low, intermediate and high Ki-67 index. The mean DFS was 98 months $(95 \%$ CI=86-110 months) in patients with a low Ki-67 index, 81 months (95\% $\mathrm{CI}=75-87$ months) in patients with intermediate $\mathrm{Ki}-67$ index and in patients with high Ki-67 index it was 68 months (95\% $\mathrm{CI}=60-76$ months). In log-rank analysis for DFS, patients with low and intermediate $\mathrm{Ki}-67$ indices had superior DFS to that of patients with high Ki-67 index (low vs. high, $p<0.001$; intermediate $v s$. high, $p=0.001$ ) (Figure 1A). 
Table I. Patient characteristics.

\begin{tabular}{|c|c|c|c|c|c|c|c|c|}
\hline & \multirow{2}{*}{$\begin{array}{c}\text { Total } \\
(n=802)\end{array}$} & \multicolumn{3}{|c|}{ Ki-67 index } & \multicolumn{4}{|c|}{ Cancer subtype } \\
\hline & & $\begin{array}{c}<10 \% \\
(n=333)\end{array}$ & $\begin{array}{l}10-20 \% \\
(n=326)\end{array}$ & $\begin{array}{c}>20 \% \\
(n=143)\end{array}$ & $\begin{array}{l}\text { Luminal A } \\
(\mathrm{n}=463)\end{array}$ & $\begin{array}{l}\text { Luminal B } \\
\qquad(\mathrm{n}=253)\end{array}$ & $\begin{array}{c}\text { HER2neu }{ }^{+/} \\
\text {non-luminal } \\
\quad(n=26)\end{array}$ & $\begin{array}{c}\text { Basal-like } \\
\quad(n=60)\end{array}$ \\
\hline Age, years & $57.52 \pm 11.88$ & $58.14 \pm 11.02$ & $57.4 \pm 11.77$ & $56.34 \pm 13.89$ & $58.38 \pm 11.06$ & $57 \pm 12.6$ & $56.12 \pm 12.45$ & $53.6 \pm 13.82$ \\
\hline \multicolumn{9}{|l|}{ T-Stage, n (\%) } \\
\hline $\mathrm{T} 1$ & $513(64.0)$ & $236(70.9)$ & $208(63.8)$ & $69(48.3)$ & $306(66.1)$ & $149(58.9)$ & $16(61.5)$ & $42(70.0)$ \\
\hline $\mathrm{T} 2$ & $257(32.0)$ & $87(26.1)$ & $111(34.0)$ & $59(41.3)$ & $143(30.9)$ & $89(35.2)$ & $10(38.5)$ & $15(25.0)$ \\
\hline $\mathrm{T} 3$ & $28(3.5)$ & $10(3.0)$ & $6(1.8)$ & $12(8.4)$ & $14(3.0)$ & $11(4.3)$ & $0(0)$ & $3(5.0)$ \\
\hline $\mathrm{T} 4$ & $4(0.5)$ & $0(0)$ & $1(0.3)$ & $3(2.1)$ & $0(0)$ & $4(1.6)$ & $0(0)$ & $0(0)$ \\
\hline \multicolumn{9}{|l|}{$\mathrm{N}$-Stage, n (\%) } \\
\hline No & $568(70.8)$ & $259(77.8)$ & $224(68.7)$ & $85(59.4)$ & $345(74.5)$ & $169(66.8)$ & $14(53.8)$ & $40(66.7)$ \\
\hline $\mathrm{N} 1$ & $164(20.4)$ & $50(15.0)$ & 77 (23.6) & $37(25.9)$ & $90(19.4)$ & $57(22.5)$ & $6(23.1)$ & $11(18.3)$ \\
\hline $\mathrm{N} 2$ & $32(4.0)$ & $7(2.1)$ & $13(4.0)$ & $12(8.4)$ & $11(2.4)$ & $15(5.9)$ & $4(15.4)$ & $2(3.3)$ \\
\hline N3 & $17(2.1)$ & $7(2.1)$ & $6(1.8)$ & $4(2.8)$ & $7(1.5)$ & $7(2.8)$ & $2(7.7)$ & $1(1.7)$ \\
\hline NX & $21(2.6)$ & $10(3.0)$ & $6(1.8)$ & $5(3.5)$ & $10(2.2)$ & $5(2.0)$ & $0(0)$ & $6(10.0)$ \\
\hline \multicolumn{9}{|l|}{ M-Stage, n (\%) } \\
\hline M0 & $510(63.6)$ & $204(61.3)$ & $206(63.2)$ & $100(69.9)$ & $286(61.8)$ & $168(66.4)$ & $14(53.8)$ & $42(70.0)$ \\
\hline MX & $292(36.4)$ & $129(38.7)$ & $120(36.8)$ & $43(30.1)$ & $177(38.2)$ & 85 (33.6) & $12(46.2)$ & $18(30.0)$ \\
\hline \multicolumn{9}{|l|}{ Grading, n (\%) } \\
\hline G1 & 93 (11.6) & $63(18.9)$ & $26(8.0)$ & $4(2.8)$ & $79(17.1)$ & $12(4.7)$ & $1(3.8)$ & $1(1.7)$ \\
\hline G2 & $579(72.2)$ & $256(76.9)$ & $255(78.2)$ & $68(47.6)$ & $362(78.2)$ & $185(73.1)$ & $13(50.0)$ & $19(31.7)$ \\
\hline G3 & $130(16.2)$ & $14(4.2)$ & $45(13.8)$ & $71(49.7)$ & $22(4.8)$ & $56(22.1)$ & $12(46.2)$ & $40(66.7)$ \\
\hline \multicolumn{9}{|l|}{ Menopausal status, n (\%) } \\
\hline Premenopausal & $246(30.7)$ & $93(27.9)$ & $103(31.6)$ & $50(35.0)$ & $134(28.9)$ & $82(32.4)$ & $9(34.6)$ & $21(35.0)$ \\
\hline Postmenopausal & $517(64.5)$ & $222(66.7)$ & $209(64.1)$ & $86(60.1)$ & $305(65.9)$ & $161(63.6)$ & $16(61.5)$ & $35(58.3)$ \\
\hline Perimenpausal & $39(4.9)$ & $18(5.4)$ & $14(4.3)$ & $7(4.9)$ & $24(5.2)$ & $10(4.0)$ & $1(3.8)$ & $4(6.7)$ \\
\hline \multicolumn{9}{|l|}{ Event, n (\%) } \\
\hline Local recurrence & $31(3.9)$ & $6(1.8)$ & $10(3.1)$ & $15(10.5)$ & $7(1.5)$ & $10(4.0)$ & $7(26.9)$ & $7(11.7)$ \\
\hline Axillary recurrence & $9(1.1)$ & $2(0.6)$ & $2(0.6)$ & $5(3.5)$ & $3(0.6)$ & $0(0)$ & $0(0)$ & $6(10.0)$ \\
\hline Distant metastasis & $45(5.6)$ & $13(3.9)$ & $18(5.5)$ & $14(9.8)$ & $22(4.8)$ & $16(6.3)$ & $2(7.7)$ & $5(8.3)$ \\
\hline Death & $16(2.0)$ & $1(0.3)$ & $8(2.5)$ & $7(4.9)$ & $3(0.6)$ & $10(4.0)$ & $1(3.8)$ & $2(3.3)$ \\
\hline \multicolumn{9}{|l|}{ Therapy, n (\%) } \\
\hline Chemotherapy & $434(54.1)$ & $140(42.0)$ & $178(54.6)$ & $116(81.1)$ & $197(42.5)$ & $165(65.2)$ & $20(76.9)$ & $52(86.7)$ \\
\hline Breast-conserving surgery & $479(59.7)$ & $225(67.6)$ & $184(56.4)$ & $70(49.0)$ & $297(64.1)$ & $135(53.4)$ & $14(53.8)$ & $33(55.0)$ \\
\hline Mastectomy & $189(23.6)$ & $63(18.9)$ & $75(23.0)$ & $51(35.7)$ & $94(20.3)$ & $66(26.1)$ & $10(38.5)$ & $19(31.7)$ \\
\hline Endocrine & $539(67.2)$ & $246(73.9)$ & $231(70.9)$ & $62(43.4)$ & $354(76.5)$ & $184(72.7)$ & $1(3.8)$ & $0(0)$ \\
\hline Radiation & $627(78.2)$ & $265(79.6)$ & $252(77.3)$ & $110(76.9)$ & $364(78.6)$ & $199(78.7)$ & $21(80.8)$ & $43(71.7)$ \\
\hline
\end{tabular}

OS was best in patients with a low $\mathrm{Ki}-67$ index compared to patients with intermediate $(p=0.006)$ and high $(p<0.001)$ indices (Figure 1B).

Multiple Cox regression analyses showed a significant association of $\mathrm{Ki}-67$ index with DFS ( $\mathrm{HR}=1.02$; 95\% $\mathrm{CI}=1.01-1.04 ; p<0.001)$. Cox regression analysis showed that patients with a low Ki-67 index had a significantly better DFS than patients with a high Ki-67 index $(\mathrm{HR}=2.85 ; 95 \%$ $\mathrm{CI}=1.45-5.59 ; p=0.002)$.

Subgroup analysis of $\mathrm{HR}^{+} / \mathrm{HER} 2 \mathrm{neu}-$ patients. A total of 667 patients were included in the $\mathrm{HR}^{+} / \mathrm{HER} 2 \mathrm{neu}^{-}$subgroup. Within this subgroup, patients with low Ki-67 index had the best mean
DFS (99 months, 95\% CI=86-112 months) compared to patients with an intermediate Ki-67 index (82 months, 95\% $\mathrm{CI}=75-88$ months) and high Ki-67 index (64 months, 95\% $\mathrm{CI}=58-70$ months) Figure $1 \mathrm{C}$. Multiple Cox regression analysis showed a significant association between Ki-67 index and DFS $(\mathrm{HR}=1.02 ; 95 \% \mathrm{CI}=1.00-1.04 ; p=0.048)$. However, patients with a low Ki-67 index showed a trend only concerning DFS compared to patients with a high $\mathrm{Ki}-67$ index $(\mathrm{HR}=2.15 ; 95 \%$ $\mathrm{CI}=0.92-4.99 ; p=0.075$ ). The Kaplan-Meier curve of OS for this group is shown in Figure 1D.

Subgroup analysis according to strict cut-off value of $14 \%$. Considering a strict cut-off value for the Ki-67 index of $14 \%$, 

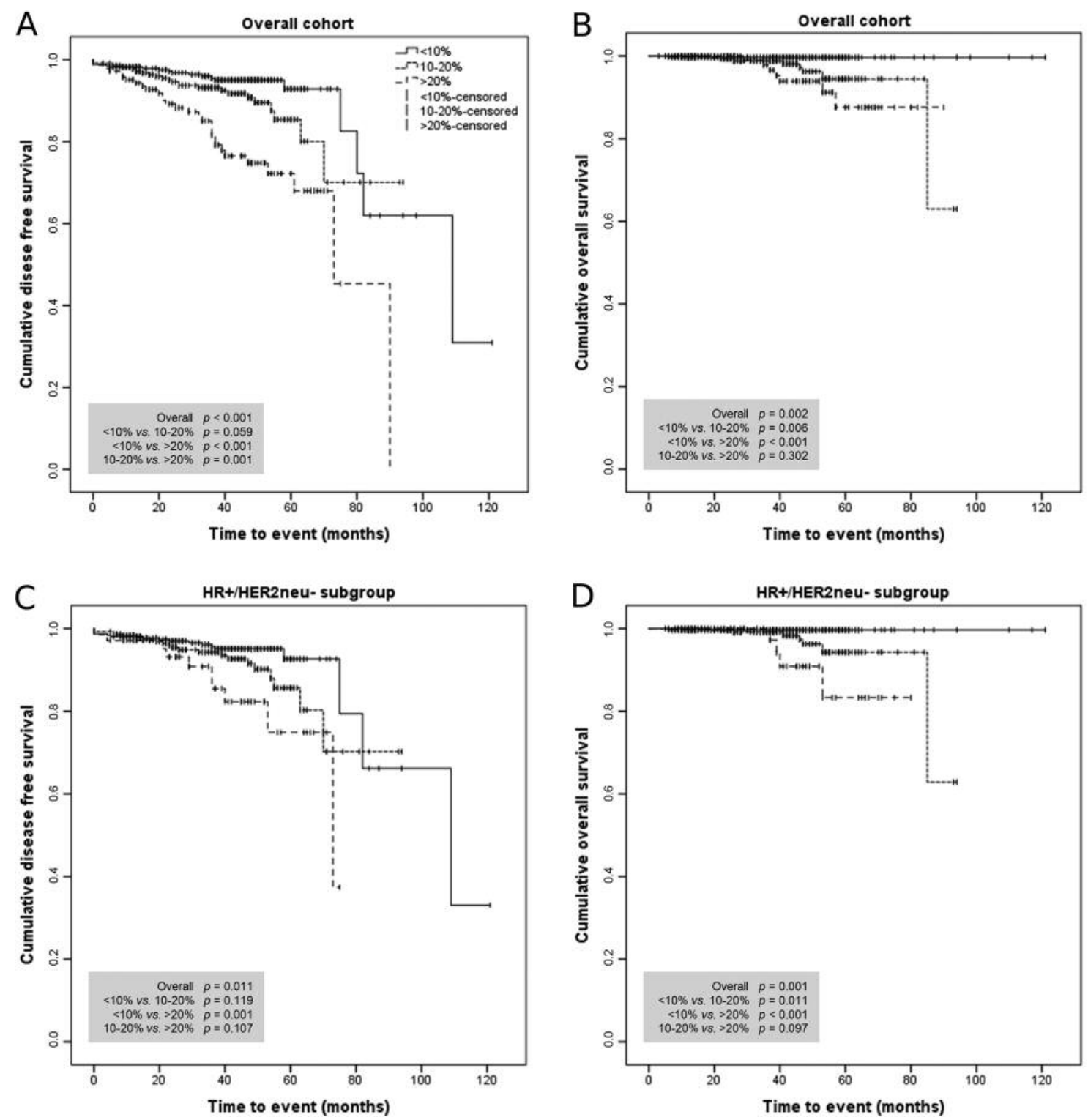

Figure 1. Kaplan-Meier curve of disease-free (DFS) and overall (OS) survival of the overall cohort (A and B, respectively) and of patients with hormone receptor positive/ human epidermal growth factor receptor 2 negative (HR+/HER2neu-) disease (C and D, respectively) based on Ki-67 index subgroups.

the study cohort is subdivided into four groups. Patients with luminal A tumors had the best mean DFS of 98 months $(95 \%$ $\mathrm{CI}=87-199$ months) compared to those with HER2neu ${ }^{+} /$nonluminal tumors (62.8 months, (95\% CI=47-79 months).

DFS and OS are presented graphically in Figure 2A and B. Cox regression analysis showed a significantly better DFS in patients with luminal A tumors compared to those with luminal B tumors $(\mathrm{HR}=1.76$; 95\% $\mathrm{CI}=1.00-3.08 ; p=0.048)$.

Luminal A versus luminal B/HER2neu- . Log-rank analysis of Kaplan-Meier curves showed that patients with luminal
A tumors had a significantly better DFS $(p=0.037)$ and OS $(p<0.001)$ compared to those with luminal B/HER2neu ${ }^{-}$ tumors (Figure 2C and D). The Cox regression analysis showed a trend concerning decreased DFS of patients with luminal B/HER2neu ${ }^{-}$tumors $(\mathrm{HR}=1.57$; 95\% $\mathrm{CI}=0.86-2.86$; $p=0.142$ ).

Luminal B/HER2neu with and without chemotherapy. Within the subgroup of those with luminal B/HER2neu ${ }^{-}$ $(n=204), 125$ patients received chemotherapy and 79 patients did not. DFS $(p=0.801)$ and OS $(p=0.379)$ were not 

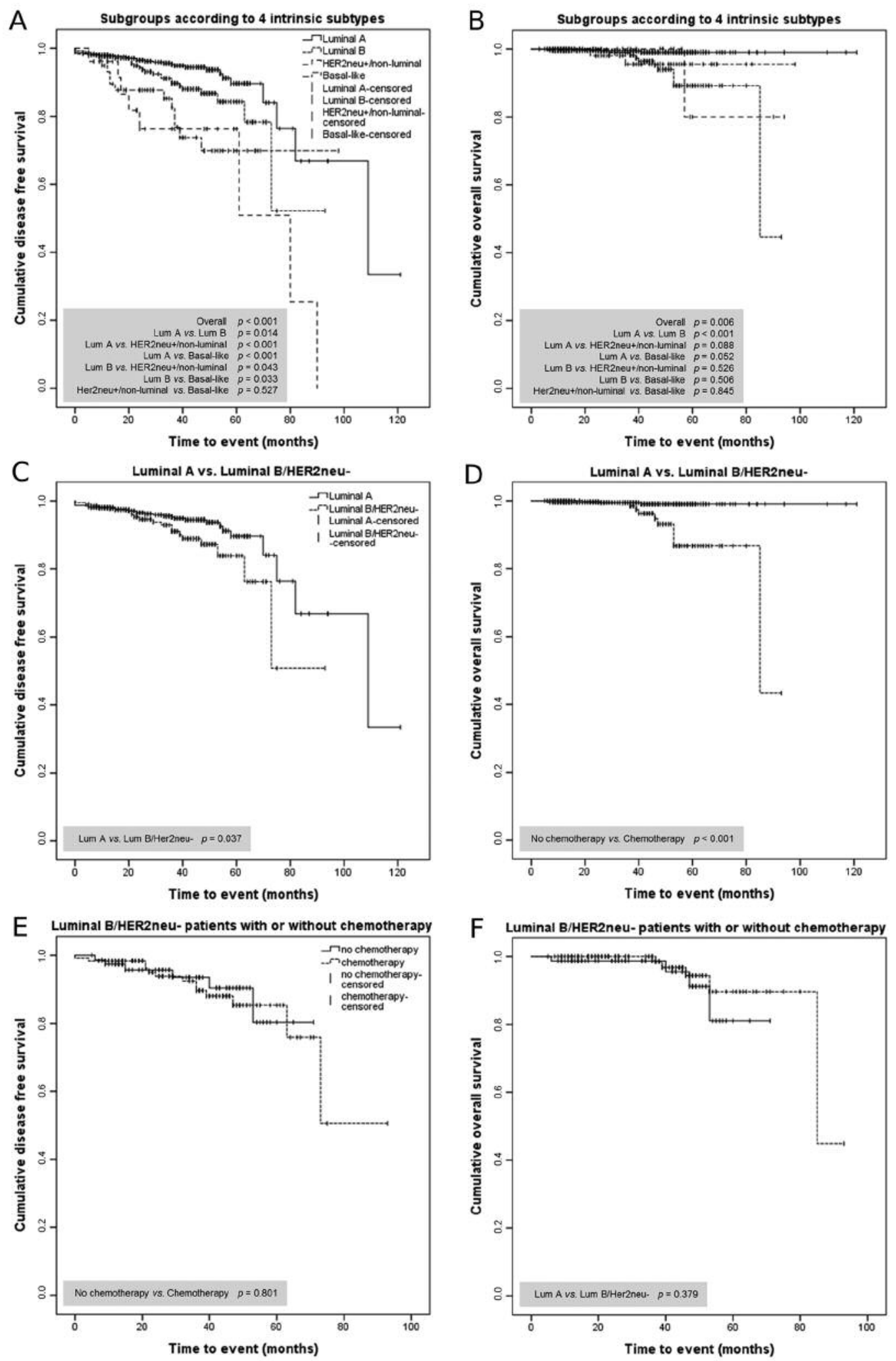

Figure 2. Kaplan-Meier curve of disease-free (DFS) and overall (OS) survival of the overall cohort according to the four intrinsic subtypes (A and $B$, respectively), of patients with HR+/HER2neu-disease ( $C$ and $D$, respectively) and according to chemotherapy in patients with luminal $B / H E R 2$ neu-disease ( $E$ and $F$, respectively). 
statistically different between these two groups (Figure 2E and F). There was no difference in application of chemotherapy concerning T-stage $(p=0.543)$ and nodal status $(p=0.35)$.

\section{Discussion}

The aim of this study was to evaluate the distribution of $\mathrm{Ki}$ 67 index in our cohort and to correlate the outcome regarding high, intermediate and low Ki-67 values. Moreover, within the subgroup of patients with $\mathrm{HR}^{+} / \mathrm{HER} 2 \mathrm{neu}^{-}$breast cancer, we used a strict cut-off of $14 \%$ to evaluate distinction between those with luminal A tumors and those with luminal B/HER2neu ${ }^{-}$tumors. The application of chemotherapy and its potential benefit in patients with luminal B/HER2neutumors was of particular clinical interest. To our knowledge, this is the largest German retrospective single-center study analyzing the prognostic and predictive significance of the Ki-67 index in patients with breast cancer.

$K i-67$ index and correlations. We were able to demonstrate a significant positive correlation between Ki-67 index and grading. This is in accordance with results of other studies $(22,23)$. In addition, we also demonstrated a significant positive correlation of $\mathrm{Ki}-67$ index with both T-stage and nodal status. The latter should be considered critically due to the high proportion of nodal-negative patients in our cohort. However, Inwald et al. did not demonstrate any correlation between Ki-67 index and T-stage, but also did show a correlation between absolute Ki-67 index and nodal status (22).

Prognostic impact of the Ki-67 index in this study cohort. One of the aims of our study was to examine the outcome of patients with low and high Ki-67 index and determine to what extent the Ki-67 index is a good prognostic parameter. We analyzed the Kaplan-Meier curves for DFS and OS. Multiple Cox regression analysis showed a significant effect of absolute Ki-67 index on DFS. In both univariate analysis $(p<0.001)$ and multiple Cox regression analysis, patients with a Ki-67 index $>20 \%$ had a significantly decreased DFS compared to patients with a low Ki-67 index (i.e. $<10 \%$ ). In univariate analysis, patients with a low Ki-67 index had improved OS compared to patients with an intermediate $(p=0.006)$ or high index $(p<0.001)$. These results show the prognostic impact of the Ki-67 index concerning DFS and its limited prognostic impact on OS. The absolute Ki-67 index can be considered an independent prognostic factor. Our results are in line with several authors $(24,25)$.

Azumbuja et al. showed in a meta-analysis that a higher $\mathrm{Ki}-67$ index is associated with a significantly higher risk for recurrent disease and a decrease in OS in univariate analysis (24). Another meta-analysis, of Stuart-Harris et al. confirmed that the Ki-67 index is an independent prognostic parameter concerning DFS and OS (25).

Prognostic impact of Ki-67 index in patients with $\mathrm{HR}^{+} / \mathrm{HER} 2 \mathrm{neu}^{-}$breast cancer. We analyzed 667 patients with $\mathrm{HR}^{+} / \mathrm{HER} 2 \mathrm{neu}^{-}$status. A multiple regression analysis showed there to be a significant effect of Ki-67 index on DFS. When comparing patients with low and high Ki-67 indices only a trend was confirmed in multiple repression analysis.

In the log-rank test, OS was significantly increased in patients with a low compared to those with an intermediate Ki-67 index $(p=0.011)$ or high Ki-67 index $(p<0.001)$. A study by Cheang et al. had similar results showing the prognostic impact of the $\mathrm{Ki}-67$ index in patients with a $\mathrm{HR}^{+} / \mathrm{HER} 2 \mathrm{neu}^{-}$tumor (26).

Viale et al. also demonstrated a significant prognostic impact of $\mathrm{Ki}-67$ index in $\mathrm{HR}^{+}$patients (27), although no predictive impact was shown. In their study, a Ki-67 index $>19 \%$ was considered a high value.

The results of our multiple regression analysis concerning patients with $\mathrm{HR}^{+} / \mathrm{HER} 2 \mathrm{neu}^{-}$status are in contrast with those of Niikura et al. (8). The study group of Niikura analyzed 1331 patients with non-metastatic breast cancer (8). They built subgroups of patients with a low $(<10 \%)$, intermediate (10-20\%) and high (>20\%) Ki-67 index and demonstrated in multivariable analysis that patients with a low index had an improved DFS compared to those with a high Ki-67 index in the group of $\mathrm{HR}^{+} / \mathrm{HER} 2 \mathrm{neu}^{-}$patients (8). Our results showed only a trend for this association $(p=0.075)$. One reason for these different results might be the higher number of cases included $(n=971)$ by Niikura et al. compared to our subgroup analysis $(n=667)$.

Subgroup analysis according to strict cut-off value of $14 \%$. Patients with luminal B tumors had a poorer DFS in multiple regression analysis compared to those with luminal A tumors. When comparing luminal A tumors with luminal B/HER2neu ${ }^{-}$ tumors, a trend for improved DFS was noticed in multivariable analysis. The results were not statistically significant however.

Hugh et al. reported similar results. They retrospectively analyzed 1350 patients and used the same cut-off value of $14 \%$ for Ki-67 index in order to distinguish between luminal A and B tumors (28). Three-year DFS was improved in patients with luminal A tumors compared to those with luminal B tumors. They also noticed that those with luminal tumors had an improved DFS compared to those with triplenegative tumors and HER2-enriched tumors (28). Voduc et al. showed that patients with luminal A tumors (cut-off for Ki-67 index: 14\%) had the best prognosis and lowest recurrence rate (29). Park et al. also showed a good prognostic impact of Ki-67 index in those with luminal A tumors and poor outcome in all other subgroups (30). 
Another study group analyzed 1691 patients with early node-negative breast cancer. They did not find any significant differences in outcome between patients with luminal A and those with B tumors (31). Those with luminal A tumors had an improved DFS compared to those with luminal B/HER2neu ${ }^{+}$and HER2-enriched and basal-like tumors (31). Differences in results compared to our results could be due to the low risk of the study cohort analyzed by Cancello et al. (31).

Our results concerning the analysis of luminal $\mathrm{A}$ and luminal B/HER2neu- tumors are in contrast with the results of Cheang et al. (26). Their study group showed that patients with luminal B/HER2neu ${ }^{-}$tumors had significantly poorer DFS and OS compared to those with luminal A tumors, regardless of whether they received adjuvant therapy (26). Cheang et al. performed a subgroup analysis with the subgroup of patients with luminal B/HER2neu ${ }^{-}$tumors due to the different adjuvant therapies given (26). Our subgroup of luminal B/HER2neu ${ }^{-}$was not subdivided into other groups and showed a heterogeneity concerning receipt of adjuvant therapies. Our results did not reveal any significant difference in DFS of patients with luminal B/HER2neu ${ }^{-}$treated with and without chemotherapy in univariate analysis.

Limitations and strengths. The retrospective character has to be considered as a limitation of the study. The common criticism about the variability of Ki-67 index between different pathologic institutes can be excluded in our study. Each Ki-67 index included in this study was assessed at the same institute. However, interobserver variability cannot be excluded.

\section{Conclusion}

Our results show that the $\mathrm{Ki}-67$ index has a prognostic impact on DFS in patients with luminal/HER2neu ${ }^{-}$tumors. The strict cut-off value for Ki-67 index was not suitable for distinguishing between a high- and low-risk collective in order to predict a response to adjuvant chemotherapy.

\section{Conflicts of Interest}

The Authors have no conflict of interests to declare in regard to this study.

\section{Acknowledgements}

The Authors thank Lotte Clement for her great support with data acquisition from ODSeasy.

\section{References}

1 Gerdes J, Schwab U, Lemke H and Stein H: Production of a mouse monoclonal antibody reactive with a human nuclear antigen associated with cell proliferation. Int J Cancer 31: 1320,1983

2 Starborg M, Gell K, Brundell E and Höög C: The murine Ki-67 cell proliferation antigen accumulates in the nucleolar and heterochromatic regions of interphase cells and at the periphery of the mitotic chromosomes in a process essential for cell cycle progression. J Cell Sci 109(Pt 1): 143-153, 1996.

3 Scholzen $\mathrm{T}$ and Gerdes J: The Ki-67 protein: from the known and the unknown. J Cell Physiol 182: 311-322, 2000.

4 Rossi L, Laas E, Mallon P, Vincent-Salomon A, Guinebretiere J, Lerebours F, Rouzier R, Pierga J and Reyal F: Prognostic impact of discrepant Ki67 and mitotic index on hormone receptorpositive, HER2-negative breast carcinoma. Br J Cancer 113: 996-1002, 2015.

5 Lopez F, Belloc F, Lacombe F, Dumain P, Reiffers J, Bernard P and Boisseau MR: Modalities of synthesis of Ki67 antigen during the stimulation of lymphocytes. Cytometry 12: 42-49, 1991.

6 Harris L, Fritsche H, Mennel R, Norton L, Ravdin P, Taube S, Somerfield MR, Hayes DF and Bast RC: American Society of Clinical Oncology 2007 update of recommendations for the use of tumor markers in breast cancer. J Clin Oncol 25: 5287-5312, 2007.

7 Urruticoechea A, Smith IE and Dowsett M: Proliferation marker Ki-67 in early breast cancer. J Clin Oncol 23: 7212-7220, 2005.

8 Niikura N, Masuda S, Kumaki N, Xiaoyan T, Terada M, Terao M, Iwamoto T, Oshitanai R, Morioka T, Tuda B, Okamura T, Saito Y, Suzuki Y and Tokuda Y: Prognostic significance of the Ki67 scoring categories in breast cancer subgroups. Clin Breast Cancer 14: 323-329.e3, 2014.

9 Goldhirsch A, Wood WC, Coates AS, Gelber RD, Thürlimann B and Senn H: Strategies for subtypes - dealing with the diversity of breast cancer: highlights of the St. Gallen International Expert Consensus on the Primary Therapy of Early Breast Cancer 2011. Ann Oncol 22: 1736-1747, 2011.

10 Dowsett M, Nielsen TO, A'Hern R, Bartlett J, Coombes RC, Cuzick J, Ellis M, Henry NL, Hugh JC, Lively T, McShane L, Paik S, Penault-Llorca F, Prudkin L, Regan M, Salter J, Sotiriou C, Smith IE, Viale G, Zujewski JA and Hayes DF: Assessment of Ki67 in breast cancer: recommendations from the International Ki67 in Breast Cancer Working Group. J Natl Cancer Inst 103: 1656-1664, 2011.

11 Reyal F, Hajage D, Savignoni A, Feron J, Bollet MA, Kirova Y, Fourquet A, Pierga J, Cottu P, Dieras V, Fourchotte V, Laki F, Alran S, Asselain B, Vincent-Salomon A, Sigal-Zafrani B and Sastre-Garau X: Long-term prognostic performance of Ki67 rate in early-stage, pT1-pT2, pN0. invasive breast carcinoma. PloS one 8: e55901, 2013.

12 Collins LC, Marotti JD, Gelber S, Cole K, Ruddy K, Kereakoglow S, Brachtel EF, Schapira L, Come SE, Winer EP and Partridge AH: Pathologic features and molecular phenotype by patient age in a large cohort of young women with breast cancer. Breast Cancer Res Treat 131: 1061-1066, 2012.

13 Colozza M, Azambuja E, Cardoso F, Sotiriou C, Larsimont D and Piccart MJ: Proliferative markers as prognostic and predictive tools in early breast cancer: Where are we now? Ann Oncol 16: 1723-1739, 2005.

14 Railo M, Lundin J, Haglund C, Smitten K von and Nordling S: $\mathrm{Ki}-67, \mathrm{p} 53$, ER receptors, ploidy and $\mathrm{S}$ phase as long-term prognostic factors in $\mathrm{T} 1$ node-negative breast cancer. Tumour Biol 28: 45-51, 2007. 
15 Trihia H, Murray S, Price K, Gelber RD, Golouh R, Goldhirsch A, Coates AS, Collins J, Castiglione-Gertsch M and Gusterson BA: Ki-67 expression in breast carcinoma: its association with grading systems, clinical parameters, and other prognostic factors - A surrogate marker? Cancer 97: 1321-1331, 2003.

16 Domagala W, Markiewski M, Harezga B, Dukowicz A and Osborn M: Prognostic significance of tumor cell proliferation rate as determined by the MIB-1 antibody in breast carcinoma: its relationship with vimentin and 553 protein. Clin Cancer Res 2: 147-154, 1996.

17 Klintman M, Bendahl P, Grabau D, Lövgren K, Malmström P and Fernö M: The prognostic value of Ki67 is dependent on estrogen receptor status and histological grade in premenopausal patients with node-negative breast cancer. Mod Pathol 23: 251259, 2010.

18 Molino A, Micciolo R, Turazza M, Bonetti F, Piubello Q, Bonetti A, Nortilli R, Pelosi G and Cetto GL: Ki-67 immunostaining in 322 primary breast cancers: associations with clinical and pathological variables and prognosis. Int J Cancer 74: 433-437, 1997.

19 Polley MC, Leung, Samuel C Y, McShane LM, Gao D, Hugh JC, Mastropasqua MG, Viale G, Zabaglo LA, Penault-Llorca F, Bartlett, John M S, Gown AM, Symmans WF, Piper T, Mehl E, Enos RA, Hayes DF, Dowsett $M$ and Nielsen TO: An international Ki67 reproducibility study. J Natl Cancer Inst 105: 1897-1906, 2013.

20 Varga Z, Diebold J, Dommann-Scherrer C, Frick H, Kaup D, Noske A, Obermann E, Ohlschlegel C, Padberg B, Rakozy C, Sancho Oliver S, Schobinger-Clement S, Schreiber-Facklam H, Singer G, Tapia C, Wagner U, Mastropasqua MG, Viale G and Lehr H: How reliable is Ki-67 immunohistochemistry in grade 2 breast carcinomas? A QA study of the Swiss Working Group of Breast- and Gynecopathologists. PloS one 7: e37379, 2012.

21 Scharl A and Kommission Mamma AGO: AGO Kommission Mamma: Diagnostik und Therapie von Patientinnen mit primärem und metastasierten Brustkrebs. 14.1.0 Edition. München: Kommission Mamma Arbeitsgemeinschaft Gynäkologische Onkologie E.V., 2014.

22 Inwald EC, Klinkhammer-Schalke M, Hofstädter F, Zeman F, Koller M, Gerstenhauer M and Ortmann O: Ki-67 is a prognostic parameter in breast cancer patients: results of a large populationbased cohort of a cancer registry. Breast Cancer Res Treat 139: 539-552, 2013.

23 Yerushalmi R, Woods R, Ravdin PM, Hayes MM and Gelmon KA: Ki67 in breast cancer: prognostic and predictive potential. Lancet Oncol 11: 174-183, 2010.

24 Azambuja E de, Cardoso F, Castro G de, Colozza M, Mano MS, Durbecq V, Sotiriou C, Larsimont D, Piccart-Gebhart MJ and Paesmans M: Ki-67 as prognostic marker in early breast cancer: a meta-analysis of published studies involving 12,155 patients. Br J Cancer 96: 1504-1513, 2007.
25 Stuart-Harris R, Caldas C, Pinder SE and Pharoah P: Proliferation markers and survival in early breast cancer: a systematic review and meta-analysis of 85 studies in 32,825 patients. Breast 17: 323-334, 2008.

26 Cheang, Maggie C U, Chia SK, Voduc D, Gao D, Leung S, Snider J, Watson M, Davies S, Bernard PS, Parker JS, Perou CM, Ellis MJ and Nielsen TO: Ki67 index, HER2 status, and prognosis of patients with luminal B breast cancer. J Natl Cancer Inst 101: 736-750, 2009.

27 Viale G, Regan MM, Mastropasqua MG, Maffini F, Maiorano E, Colleoni M, Price KN, Golouh R, Perin T, Brown RW, Kovács A, Pillay K, Ohlschlegel C, Gusterson BA, Castiglione-Gertsch M, Gelber RD, Goldhirsch A and Coates AS: Predictive value of tumor Ki-67 expression in two randomized trials of adjuvant chemoendocrine therapy for node-negative breast cancer. J Natl Cancer Inst 100: 207-212, 2008.

28 Hugh J, Hanson J, Cheang, Maggie Chon U, Nielsen TO, Perou CM, Dumontet C, Reed J, Krajewska M, Treilleux I, Rupin M, Magherini E, Mackey J, Martin M and Vogel C: Breast cancer subtypes and response to docetaxel in node-positive breast cancer: use of an immunohistochemical definition in the BCIRG 001 trial. J Clin Oncol 27: 1168-1176, 2009.

29 Voduc KD, Cheang, Maggie C U, Tyldesley S, Gelmon K, Nielsen TO and Kennecke H: Breast cancer subtypes and the risk of local and regional relapse. J Clin Oncol 28: 1684-1691, 2010.

30 Park S, Koo JS, Kim MS, Park HS, Lee JS, Lee JS, Kim SI and Park B: Characteristics and outcomes according to molecular subtypes of breast cancer as classified by a panel of four biomarkers using immunohistochemistry. Breast 21: 50-57, 2012.

31 Cancello G, Maisonneuve P, Rotmensz N, Viale G, Mastropasqua MG, Pruneri G, Montagna E, Dellapasqua S, Iorfida M, Cardillo A, Veronesi P, Luini A, Intra M, Gentilini O, Scarano E, Goldhirsch A and Colleoni M: Prognosis in women with small (T1mic,T1a,T1b) node-negative operable breast cancer by immunohistochemically selected subtypes. Breast Cancer Res Treat 127: 713-720, 2011. 